\title{
Above-Ground Resource Analysis with Spatial Resolution to Support Better Decision Making
}

\author{
Xuan $\mathrm{Zhu}^{1} \cdot$ Xiaobo $\mathrm{Yu}^{2}$
}

Published online: 14 March 2016

(C) The Minerals, Metals \& Materials Society (TMS) 2016

\begin{abstract}
Understanding how much of above-ground resources are present, where the stocks are located, and how they are distributed, is important for the evaluation of the economic values of the resources, the social, and environmental impacts of mining these resources and the effectiveness of existing and future collection and recovery systems. Although the value of geographical location has recently been recognized in above-ground resource analysis, new ways to use the concept of place and location to organize and analyze information are required to enable better policy, planning, information dissemination, and communication. This paper first discusses the value of location in policy and decision making about above-ground resource use and management, reviews the top-down and bottom-up methods for above-ground resource analysis, then presents a geographical information systems (GIS) approach to above-ground resource analysis, and finally implements the approach to the construction of a spatially enabled database of above-ground copper, zinc, and steel in-use stocks at various levels of geographical regions in Australia. It demonstrates that the integration of GIS and the bottom-up method allows above-ground metal stock data to be processed, analyzed, and presented at multiple spatial scales to support policy and decision making at
\end{abstract}

The contributing editor for this article was Veena Sahajwalla.

Xuan Zhu

xuan.zhu@monash.edu

1 School of Earth, Atmosphere and Environment, Monash University, Clayton Campus, Clayton, VIC 3800, Australia

2 Centre for Geography and Environmental Science, Monash University, Clayton Campus, Clayton, VIC 3800, Australia various spatial levels with management and planning significance.

Keywords Urban mining - Metal recycling - Aboveground resource analysis · GIS · In-use metal stock

\section{Introduction}

"Above-ground resources" can mean different things to different people. Here it means the metal stocks in society served as mines above ground, which is also called urban mine. These include the metals contained in buildings, urban infrastructure, transport systems, motor vehicles, equipment, electronic devices (e.g., mobile phones, computers, tablets, TVs and similar gadgets), and landfill stockpiles. According to a report on metal stocks in society, published in 2010 by the International Resource Panel hosted by the United Nations Environment Programme (UNEP), during the twentieth century, the variety of metals used in society grew quickly, which leads to expanding metal mining activities, and creating more and more of the world's metal stocks that are above ground in use rather than below ground as unused reserves [1]. The utilization of these growing metal stocks through recycling is expected to be an important source for metal supply in the future [2] [3, 4].

However, to mine these resources, we need information about how much of the resources are present, in which form, and at which location [5]. Above-ground resource analysis aims to provide this kind of information. Such information is essential for evaluation of the economic values of the resources, the social and environmental impacts of mining these resources, effectiveness of existing collection and recovery systems, and for building a 
recycling infrastructure in the future. Therefore, they allow governments, metal processing and recycling industries to make more intelligent and targeted decisions on urban mining, production, and waste management.

There is a growing recognition of the value of geographical location in above-ground resource analysis. This is because all buildings have an address, all urban infrastructure and other metal-containing products are located at some physical locations. The amount of metal stock at a location depends on the number or density of metal-containing products at that location. This varies from location to location. In other words, there exist spatial variations in the distributions of metal stocks. Above-ground resources data related to the location can be analyzed in ways that will contribute policy and business insight among a variety of operational and analytical dimensions, e.g., developing plans for metal recovery and reuse, evaluating metal losses to the environment during use, estimating costs to the anticipated markets, predicting future metal and discard demand, and other ways of generating positive social, economic, and environmental values.

Studies have been undertaken to incorporate location into above-ground resource analysis. Such a type of analysis is labeled as "spatially enabled above-ground resource analysis". For example, van Beers and Graedel [6] analyzed the spatial patterns of the in-use stocks of copper and zinc in Australia at four spatial scales (central city, urban region, states/territories, and country). Rauch [7] produced global maps of aluminum, copper, iron, and zinc in-use stocks and in-ground resources. Tanikawa and Hashimoto [8] estimated construction material stocks over time with spatio-temporal data in a Japanese city and a British city. Zhang et al. [9] investigated the spatial and temporal patterns of copper in-use stocks in China. Liu and Müller [10] simulated the evolution of global aluminum in-use stocks in geological reserve and anthropogenic reservoir from 1900 to 2010 on a country level. However, location-based material stock information has so far been generated largely for research purposes [6], and for providing in-use stock estimates at city or national levels. They are not accessible to governments, businesses, and the general public, and mostly do not support multi-scale aboveground resource analysis. We contend that new ways to use the concept of location to organize information are required to inform policy and decision making at various spatial scales and enable better policy, planning, operation, information dissemination, and communication. In this paper, we first discuss the value of location in aboveground resource analysis, then review the methods for above-ground resource analysis, and finally present a GIS (geographical information systems) approach to aboveground resource analysis using Australia as a case study. The case study focuses on copper, zinc, and steel in-use stocks estimated at various levels of geographical regions in Australia, and uses GIS to spatially enable, visualize, and analyze in-use metal stock information at multiple spatial scales.

\section{Value of Location in Above-Ground Resource Analysis}

Above-ground resource analysis has been conducted within the framework of material flow analysis or accounting. Material flow analysis is to quantify flows and stocks of materials or above-ground resources within a system defined in space and time. It aims to capture the mass balances in an economy, where total inputs (extractions + imports) equal outputs (consumptions + exports + wastes) plus net stock accumulation, and thus is based on the laws of thermodynamics [11].

Above-ground resources are closely linked to productivity and the material standard of living of a society. They provide services and are accumulated and maintained through material flows. The amount, age, and growth of above-ground resources explain the demands for materials (inputs) and potentials for recycling (outputs). Most of the current material flow analyses focus on the amount of material passing through a system, while material stocks or the amount and distribution of above-ground resources have received less attention in research [12]. Particularly the spatial distribution of above-ground resources has been largely neglected. In most cases, the numeric indicators used in material flow analysis are derived from economic data at the national level and characterize the above-ground resources from economic and population perspectives [12, 13]. They may be linked to a particular territory, but using them in numeric terms spatial dimensions are lost. As a result, data and information derived from material flow analysis largely do not directly support policy making [2], and have limited application in regional and local planning or other locally driven sustainable development policy. Such data and information also provide no or very limited business insight for metal processing and recycling industries to make business cases.

As the major metal-containing products, such as buildings and infrastructure, are fixed assets, taking up physical space on land, location determines the distribution, density, accumulation, value, and trend of metal stocks as well as a sustainable metal resource throughput. It is important to know the location of metal resources in addition to their quantity and quality to consider them for future mining [14]. In addition, policy and decision making using aboveground resource data and information may take place at different levels. At the national level, above-ground resource information can provide insights into the physical 
structure and change over time of the metabolism of the national economy, and can be used for deriving indicators for resource productivity and efficiency and for various policy-oriented analyses of economy-environment interactions [13]. At the local government level, above-ground resource information can be used to support local government developmental and service planning and influence policies for the built environment. For example, it can help develop policies and guidelines on how, where, and what type of housing should be constructed, and when and how buildings are demolished and materials recovered and reused. It also provides useful information to assess current collection and recovery infrastructure and plan new infrastructure. To support decision and policy making in individual companies or organizations such as metal processing, production and recycling industries, public health and environmental agencies, and public policy organizations, above-ground resource analysis should be conducted at a variety of spatial and temporal scales to provide the basis for the development of scenarios of metal demands and discards from stock in use [3]. All these levels of policy and decision making are differentiated on the basis of system boundaries, which are interpreted to be spatial and based on the geographical locations. Therefore, the values, validity, and usefulness of above-ground resource information depend on the spatial level at which the analysis is conducted and at which influential policy or business decisions are made. This requires above-ground resource information to be provided at different spatial scales.

Location is the basis for multi-scale above-ground resource analysis. With locations, above-ground resources can be aggregated at any level of geographical regions, for example from local government areas to states and then to the entire nation. They allow comparisons with aggregated socio-economic and demographic indicators such as the gross domestic product (GDP) and unemployment rates, and normalization of in-use stock estimates, therefore, provide policy makers with information they are used to handling.

\section{A GIS Approach to Above-Ground Resource Analysis}

GIS is a proven technology for collecting, managing, analyzing location-based data and information, and producing location intelligence [5]. It can be used to support multi-scale above-ground resource analysis based on locational information about metal stocks. There are two methods commonly used for above-ground resource analysis: top-down and bottom-up [3].

The top-down method derives in-use metal stock from the cumulative difference between inflow (metal demand) and outflow (metal discard). Mathematically, it calculates in-use metal stocks as [3]:

$S_{t}=\sum_{i=1}^{t-1}\left(F_{t-i}^{\mathrm{in}}-F_{t-i}^{\mathrm{out}}\right)+S_{0}$,

where $S_{t}$ is the in-use stock in year $t, S_{0}$ is the stock in the initial year, $F_{t-i}^{\text {in }}$ is the inflow in year $t-i$, and $F_{t-i}^{\text {out }}$ is the outflow in year $t-i$. This method takes time series of historical data on metal demands and discards, and calculates in-use stock by adding the annual difference of inflow and outflow over time. Typically, $t$ ranges from 50 to 100 years or longer [3]. Inflow data are usually provided by production, trade, and consumption statistics. Outflows are often estimated using a product's lifetime distribution density function [2]. The results of the top-down method are highly aggregated and generally contain no information about the spatial distribution of above-ground resources. This method is also difficult to link to demand for services.

The bottom-up method directly measures the stocks in all the metal-containing products or end-use sectors at a specific time and then sums them up, as expressed in the following equation [3]:

$S_{t}=\sum_{k=1}^{N}\left(n_{k, t} \times m_{k, t}\right)$,

where $n_{k, t}$ is the quantity of product in use or end-use sector $k$ in year $t, m_{k, t}$ is the average or typical metal content of product or end-use sector $k$ in year $t, N$ is the number of product groups or end-use sector categories. Metal contents are measured in material weight per physical unit of a product, and are usually time variant. The bottom-up method estimates the entire stock of a specific metal from all product groups or end-use sectors containing that metal, located in a specific area at a particular time. As it is usually based on data collected from small-area statistics (such as housing statistics and land accounts at the city/town or lower levels of areal aggregation) or detailed spatial or map databases (such as cadastral map data and transport network data), the bottomup method can be used to accurately characterize the spatial pattern of in-use metal stocks and directly link in-use stocks and services. However, Müller et al. [2] reviewed 60 studies of metal flow analysis published before 2014 and found that about $90 \%$ of them applied the top-down method and only $10 \%$ used the bottom-up method. That is because the bottom-up method is data intensive and requires extensive data collection. It was often hindered by the difficulty to count everything in use and by uncertainties concerning the metal content of many of the products $[2,3,6,15,16]$. But the increasing availability of GIS data on the urban environment and infrastructure as well as data on consumers and services has opened the door to more applications of the bottom-up method. 
Naturally, GIS is an effective and efficient tool for implementing the bottom-up method. With time series of GIS data on buildings, infrastructure, and other stocks of interest, GIS can be used to produce above-ground resource information with high spatial and temporal resolutions, which can support multi-level policy and decision making. Here we propose a GIS approach to above-ground resource analysis. It is built upon the bottom-up method. This approach consists of six steps (Fig. 1).

\section{Step 1 Problem Definition}

This involves defining the purpose of above-ground resource analysis, the metal types, the product groups or end-use sectors containing those metals, the temporal scale, the system (or spatial) boundaries, and the mapping units. System boundary definition is essential, since small boundary adjustments can have large impacts on final stock estimates. The system boundary may correspond with administrative or political boundaries, or geographical areas for the collection and dissemination of geographical

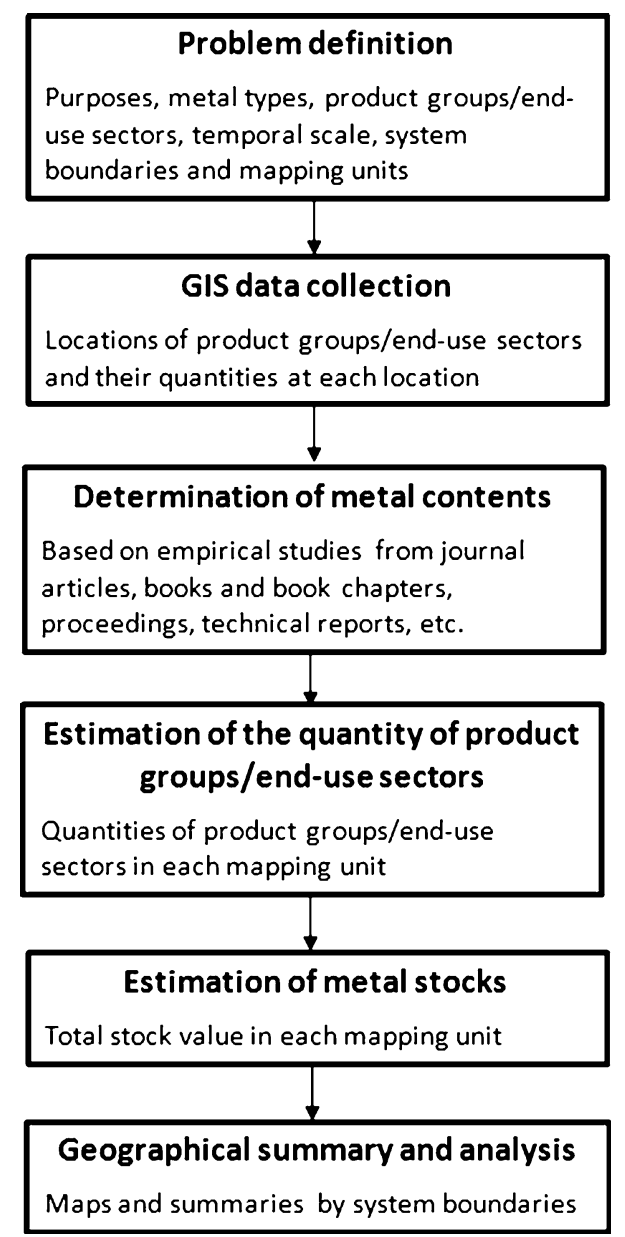

Fig. 1 A GIS approach to above-ground resource analysis statistics such as those defined in the Australian Statistical Geography Standard [17]. Each of these boundary definitions will have a significant impact on the final results. The selected system boundaries should have policy, management, or planning significance. The mapping units are the area units at the lowest level of geographical aggregation for stock estimation, which may correspond to the smallest system boundary defined above.

\section{Step 2 GIS Data Collection}

GIS data have a locational component defining the physical locations of objects on the surface of the Earth [5]. They are also called spatial or georeferenced data. Digital map layers and georeferenced remote sensing images are the major forms of GIS data. The fundamental GIS data for above-ground resource analysis are locations and sizes or quantities of the defined metal-containing products (such as residential buildings, industrial buildings, rail lines, motor vehicles, and household appliances) or end-use sectors (such as infrastructure, transport, buildings, and equipment). In recent years, GIS data on buildings, transport, infrastructure, and social, economic, and demographic indicators have been made available through the national spatial data infrastructure in many countries. Many of such data are often available at the city or lower levels of aggregation. If the required GIS data on the defined metalcontaining products or end-use sectors are not already available, secondary data sources need to be identified.

\section{Step 3 Determination of Metal Contents}

The typical metal contents of the defined products or enduse sectors are the key parameters for metal stock estimation using the bottom-up approach as indicated in Eq. (2). They are determined by reviewing existing empirical studies on metal stocks and flows. If not enough applicable studies are available, additional studies may have to be located, and the results summarized. Where no studies exist in the literature, new empirical studies may need to be conducted. Journal articles, books and book chapters, proceedings, technical reports, Ph.D. dissertations, and public raw data are the main sources of empirical studies on metal contents.

\section{Step 4 Estimation of the Quantity of the Metal- Containing Products or End-Use Sectors}

The map algebra functions in GIS are used to calculate the quantities of the metal-containing products or end-use sectors within each mapping unit using the GIS data collected in Step 2. This provides the parameter values for $n_{k, t}$ in Eq. (2). 
Table 1 Proxy indicators and material contents for copper stock estimation (adapted from van Beers and Graedel [6])

\begin{tabular}{llll}
\hline End-use sector & Proxy indicator & Unit & $\begin{array}{l}\text { Material content } \\
\text { (kg Cu/unit) }\end{array}$ \\
\hline Building and construction & Single family house & Dwelling & 195 \\
& Semi-detached and apartment & Dwelling & 110 \\
& Other dwelling type & Dwelling & 65 \\
Infrastructure & Single family house & Dwelling & 72 \\
(Power distribution) & Semi-detached and apartment & Dwelling & 48 \\
& Other dwelling type & Dwelling & 24 \\
Infrastructure & Single family house & Dwelling & 7 \\
(Telecommunication) & Semi-detached and apartment & Dwelling & 7 \\
& Other dwelling type & Dwelling & 7 \\
Transportation & Passenger motor vehicle & Vehicle & 14 \\
Consumer durables & Low income household & Household & 19 \\
& Medium income household & Household & 39 \\
& High income household & Household & 58 \\
\hline
\end{tabular}

\section{Step 5 Estimation of the Metal Stocks}

Once each mapping unit is assigned a quantity of a particular product or end-use sector, it can then be assigned a metal content multiplier from step 3 . The total stock value of a mapping unit is then calculated by adding up the stocks in individual products or end-use sectors according to Eq. (2)

\section{Step 6 Geographical Summaries and Analysis}

The stocks of a specific metal calculated in the fifth step can be mapped by the original mapping unit, or summarized by the system boundaries defined in step 1 . In this way, multi-scale above-ground resource data are obtained. These data constitute a spatially enabled above-ground resource database. With GIS data management, spatial analysis, and visualization functions, the data from the database can be retrieved, mapped, and integrated with other GIS datasets for further analysis or modeling.

The GIS approach outlined above has been implemented for above-ground resource analysis of copper, zinc, and steel in-use stocks in Australia.

\section{Case Study}

Australia is a developed country with a high level of urban material stocks and waste generation. According to Golev and Corder [18], metal consumption in Australia grew from 8.8 to 12.3 million tons from 2002 to 2011 , and the amount of generated metal waste is estimated to have grown from about 5 to 6 million tons. However, existing data on metal flows in Australia are relatively coarse and usually quite aggregated spatially and by economic sectors, which limits the usability of the data for analyses and decision support. In order to overcome the data limitations, we constructed a spatially enabled database of above-ground copper, zinc, and steel in-use stocks across Australia at various spatial levels using the GIS approach outlined above and developed a Web interface to the database for mapping and analysis.

In the case study, we identified four major end-use sectors of copper and zinc, including building and construction, infrastructure, transport, and consumer durables. The average copper and zinc contents of each end-use sector were estimated using the proxy indicators suggested by van Beers and Graedel [6], which are listed in Tables 1 and 2. The data on the proxy indicators come from the 2011 Australian Census.

Steel in-use stock was currently estimated for the Monash local government area (LGA) in Melbourne only and limited to the stocks in metal roofs of buildings. The aerial photos and LiDAR (Light Detection And Ranging) data covering the LGA were used to delineate roof boundaries and identify metal roofs. Building roof boundaries were extracted using the three-step method proposed by Kim et al. [19]:

- First, a digital surface model was built from LiDAR data, which was used to extract high objects based on the pre-determined height threshold.

- Then, a supervised classification was conducted on the aerial photos to identify forest areas or trees among the high objects.

- Finally, an area-based filter was applied to eliminate small areas, such as noise, thus extracting building objects from which the building boundaries were derived.

Metal roofs were identified through the visual interpretation of the aerial photos. Steel stock in a roof $S_{\mathrm{Fe}}$ is calculated as 
Table 2 Proxy indicators and material contents for zinc stock estimation (adapted from van Beers \& Graedel [6])

\begin{tabular}{llll}
\hline End-use sector & Proxy indicator & Unit & $\begin{array}{l}\text { Material content } \\
\text { (kg Zn/unit) }\end{array}$ \\
\hline Building and construction & Single family house & Dwelling & 290 \\
& Semi-detached and apartment & Dwelling & 188 \\
& Other dwelling type & Dwelling & 52 \\
Transportation & Passenger motor vehicle & Vehicle & 12 \\
& Tire passenger vehicle & Tire & 0.25 \\
Consumer durables & Low income household & Household & 34 \\
& Medium income household & Household & 68 \\
& High income household & Household & 102 \\
\hline
\end{tabular}

$S_{\mathrm{Fe}}=m_{\mathrm{Fe}} \times A \times P_{\mathrm{Fe}}$,

where $m_{\mathrm{Fe}}$ is the iron content $\left(\mathrm{kg} / \mathrm{m}^{2}\right), A$ is the roof size $\left(\mathrm{m}^{2}\right)$, and $P_{\mathrm{Fe}}$ is the percentage iron content $(\%)$.

According to the technical report from BlueScope Steel Australia [20], most residential and commercial metal roofing material is manufactured with around 97-99\% steel and $1-3 \%$ of coating like zinc and aluminum. We used the average iron content of $10.5 \mathrm{~kg} / \mathrm{m}^{2}$ and percentage iron content of $98 \%$ in Eq. (3).

The mapping unit is the statistical area level 1 (SA1), which is the smallest area unit for the Census data release in Australia [17]. There are approximately 55,000 SA1 s covering the whole of Australia. An SA1 covers an area having a population of 200-800 persons, and an average population of about 400 persons. Following steps $4-6$ described in the previous section, we constructed a GIS database of aboveground copper, zinc, and steel in-use stocks of Australia. Through the Web interface, stock data can be retrieved and mapped by SA1 in a Web browser. At the moment, the system allows the stock data to be aggregated from SA1 to five higher levels of system boundaries, including suburbs, postcode areas, local government areas, greater capital city areas, and states and territories. A user can select one of the six types of system boundaries to map above-ground in-use copper, zinc, and steel (limited to one local government area) stocks across Australia. Figure 2 shows copper in-use stocks in dwellings mapped at the state, postcode area, suburb, and SA1 levels. Figure 3 is a map of steel in-use stocks in the Monash local government area at the SA1 level. All the maps are interactive. Taken together, the maps created from the database show the heterogeneity in the spatial distribution of above-ground copper, zinc, and steel resources across Australia at every level of area aggregation.

\section{Discussion and Conclusions}

Spatially enabled above-ground resource analysis can be applied to various spatial scales and different types of systems, such as neighborhoods, cities/towns, counties, states, countries, and world regions, or households, companies, economic sectors, national economies, and the world economy. This paper presents a GIS approach that implements the bottom-up method to spatially enabled above-ground resource analysis and applies the approach, as a case study, to develop a GIS database of copper, zinc, and steel in-use stocks of Australia and a Web application for the access, mapping, dissemination, and communication of the above-ground in-use metal stock data in the database. The GIS database and Web application allow the choice of scale, level, and extent, which is central to aboveground resource analysis, thus supporting multi-level analysis. The customary levels for in-use stock determinations are SA1, suburbs, postcode areas, local government areas, greater capital city areas, and states and territories. The choice of a level establishes the system boundary. The in-use stock data can be used by all levels of government to support public policy making regarding above-ground metal resource use, recovery, and management, environmental impact assessment, future metal demand prediction, and investment planning in urban mining and waste management infrastructure, and to help metal processing, production, and recycling industries develop scenarios of metal demands, discards, or future metal scrap flows. In addition, the data can be accessed by the public to improve their awareness of metal resources that are literally stored under their feet and in their direct living environment, and used directly by researchers as input data for material flow analysis and life cycle assessment.

The GIS approach has a number of advantages. First, it supports multi-scale, spatially explicit above-ground resource analysis as mentioned above. Second, GIS supports systematic collection and integration of spatial data based on a common georeferencing system and spatial data structure [5]. It provides capabilities to organize, structure, and integrate spatial data and ensure their consistency. Through their underlying data structure, above-ground resource data in a GIS database can be easily integrated with socio-economic, demographic, and environmental data available from statistical databases or economic 
a

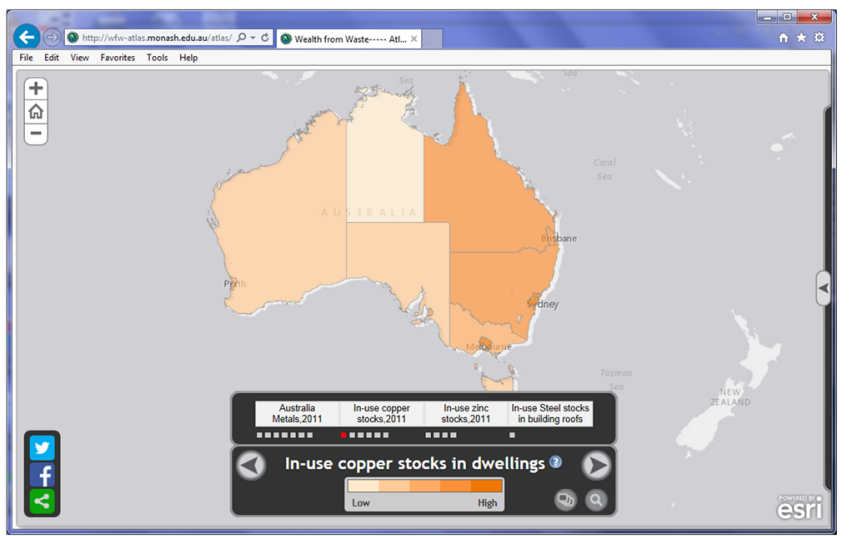

C

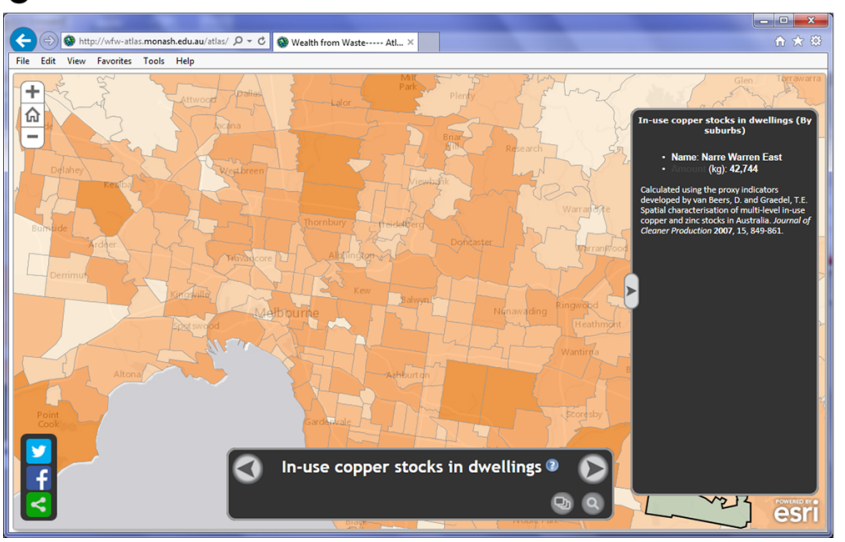

b

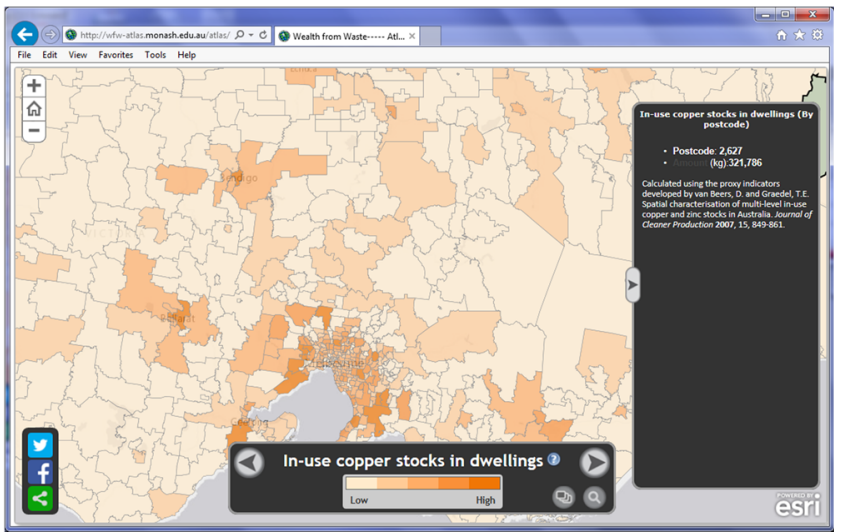

d

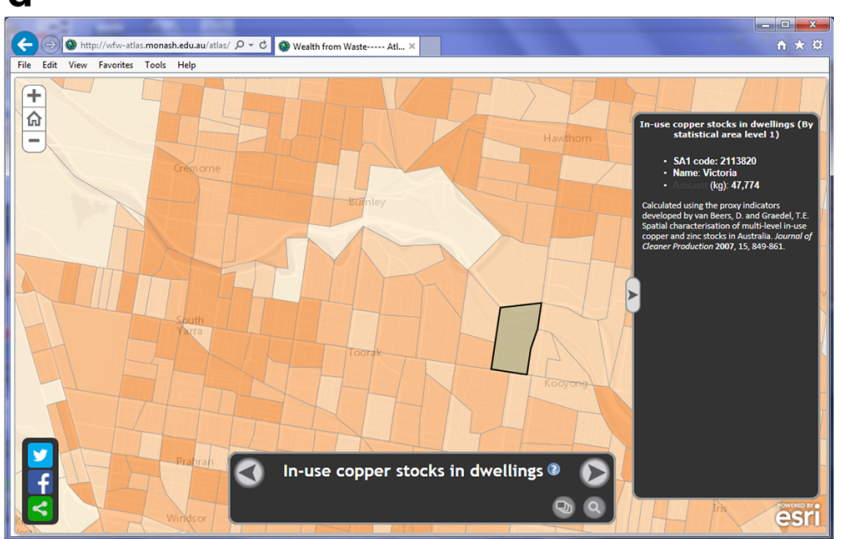

Fig. 2 Copper stocks in dwellings a by states and territories, $\mathbf{b}$ by postcode areas, $\mathbf{c}$ by suburbs, and $\mathbf{d}$ by SA1

accounting systems (such as census and land accounts) and other GIS databases. For example, we can incorporate population data into our stock database to normalize in-use stock estimates by population, or add land use data into the database to establish the link between the intensity of metal use and that of land use. Third, GIS can handle spatiotemporal data that capture spatial and temporal aspects of above-ground resources. Using this capability, aboveground resource data of multiple periods of time can be integrated into a single stock database, which allows for the analysis of dynamics of above-ground resources, and historic and future trends of above-ground resource use. This effectively incorporates the detail of the bottom-up method with the temporal aspect of the top-down method, and provides a platform for combining the bottom-up and topdown methods for above-ground resource analysis. Furthermore, a GIS database can be developed incrementally. The development of a spatially enabled above-ground resource database within the GIS environment may start with a few metal-containing products or end-use sectors or several small areas for a single year, as we did in the case study. More products or end-use sectors and stock data of different years can be added when the data become available. Thus, a GIS database of above-ground resources is cumulative and expandable. Finally, mapping or spatial visualization with GIS allows the knowledge of aboveground resources to be presented in a simple, intuitive and comprehensive way, therefore facilitates the diffusion of scientific knowledge resulted from above-ground resource analysis to policy and decision makers as well as the general public.

While this paper offers a GIS approach to spatially enabled above-ground resource analysis, lessons were learnt from the case study described above. The basic data for above-ground resource analysis with the GIS approach include spatial data of metal-containing products or enduse sectors (including both locations and quantities), and metal contents of these products or end-use sectors. The availability of data or empirical studies on metal contents is one of the most significant constraints to this approach. In our case study, metal content data are from another Australian study, which were elicited from interviews to industry experts, professional bodies and associations [6]. For many products in use, such as electronics, cars and machinery, metal content can be measured or obtained from manufacturers. For products such as buildings, it is 


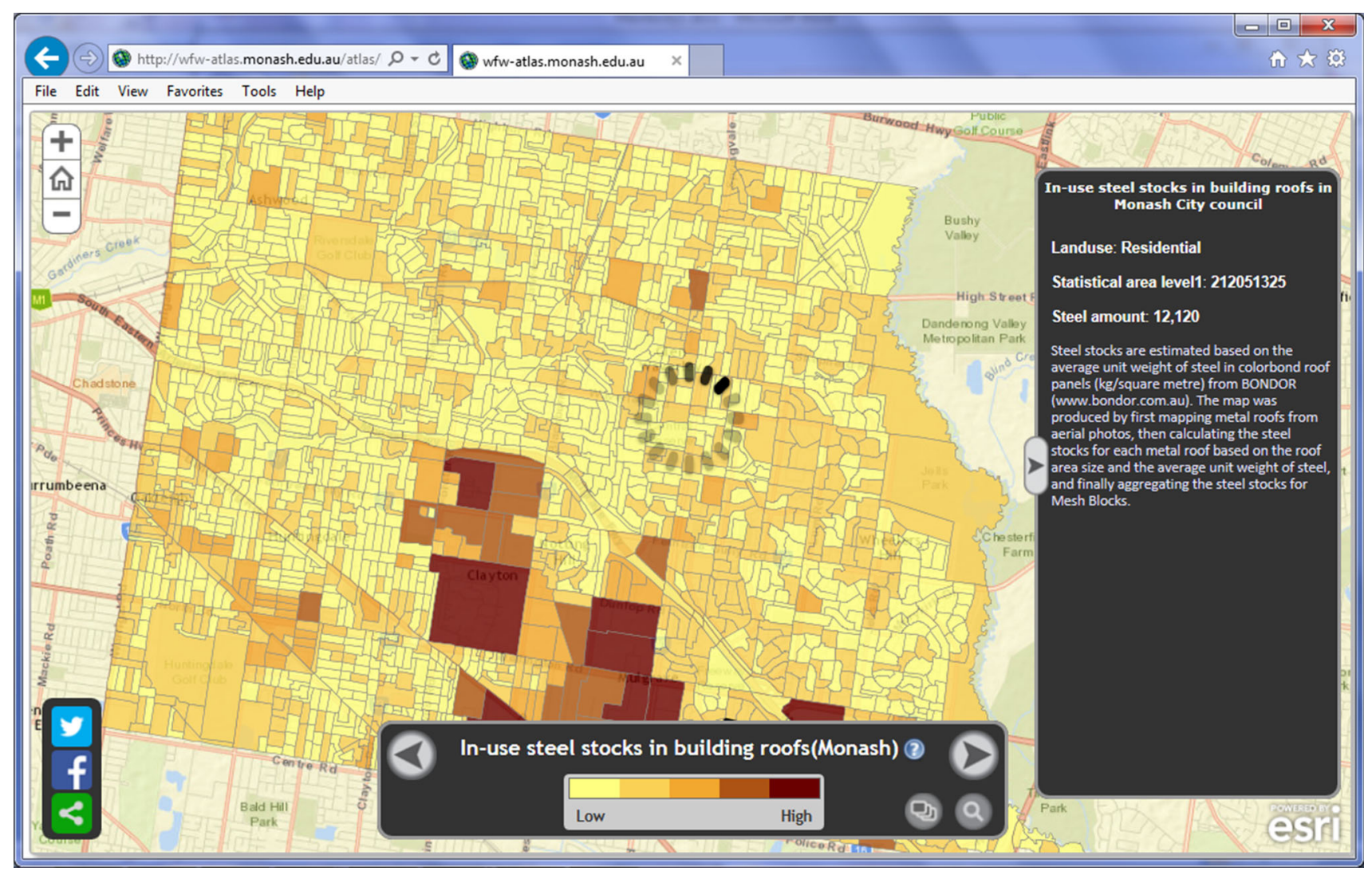

Fig. 3 Steel stocks in building roofs in the Monash local government area by SA1

more difficult to estimate as every building could be different. In addition, metal contents in many products vary over time. For example, the copper content of a house built in the 2000s could be quite different from a house built in the 1960s. To estimate the metal contents in such products requires either a survey of the metal contents of the products in use or an investigation of relevant historical engineering design plans or codes of construction [3]. Development of a material content database is data and labor intensive, but it is necessary for accurate and reliable estimation of metal stocks with the GIS approach.

A further factor complicating the implementation of this approach is the availability of spatial data. As shown in the case study, some product groups (such as commercial motor vehicles, industrial and commercial buildings, business electrical and electronic products, and industrial machinery and equipment) containing copper, zinc, and steel are missing from the GIS database due to the lack of relevant spatial data. However, the development of the Australian database of copper, zinc, and steel in-use stocks is still ongoing. New sources of data have been identified and the data gaps will be filled. Moreover, the current database provides a 1-year snapshot only. We are sourcing historical data sets so that dynamic analysis of metal stocks and metal flow modeling become possible.
Perhaps the most important lesson learned from the case study relates to how to make use of the data from the GIS database. The database and Web application have been presented in a couple of workshops participated by academics, industrial representatives and governmental officials. Although the potential users of the database have been identified as discussed above, it was found that in-use metal stock information by itself has limited value. As Gerst and Graedel [3] pointed out, the value of such information is manifest only when it is used to produce scenarios of future metal use, discard, recovery, and reuse. One of the future directions of our study will be on understanding the needs of the potential users through social surveys and developing metal demand, discard, and reuse scenarios to meet the users' needs based on different assumptions of population growth, technological advancement, and other relevant factors using our expanded GIS database.

We anticipate that the GIS approach described in this paper will be refined and improved as the empirical literature on metal stock and flow analysis grows and the availability of metal content and spatial data increases. The increasing quality and availability of fine-scale social, economic, regulatory, and infrastructural spatial data are also promising for future above-ground resource analysis. 
By providing reliable metal stock and flow estimates with multiple levels of spatial and temporal resolutions, we can assist decision makers in the private sector and government to develop strategies and plans for sustainable aboveground resource use and management.

Acknowledgments The authors would like to acknowledge the support of the Wealth from Waste Research Cluster, a collaborative program between CSIRO (the Commonwealth Scientific and Industrial Research Organisation); University of Technology, Sydney; Monash University; the University of Queensland; Swinburne University of Technology; and Yale University.

\section{References}

1. The United Nations Environment Programme (UNEP) (2011) Metal stocks in society-scientific synthesis. UNEP, Paris

2. Müller E, Hilty L, Widmer R, Schluep M, Faulstich M (2014) Modeling metal stocks and flows-a review of dynamic material flow analysis methods. Environ Sci Technol 48:2102-2113. doi:10.1021/es403506a

3. Gerst MD, Graedel TE (2008) In-use stocks of metals: status and implications. Environ Sci Technol 42(19):7038-7045. doi:10. 1021/es800420p

4. Pauliuk S, Wang T, Müller DB (2013) Steel all over the world: estimating in-use stocks of iron for 200 countries. Resour Conserv Recy 71:22-30. doi:10.1016/j.resconrec.2012.11.008

5. Zhu X (2014) GIS and urban mining. Resources 3:235-247. doi:10.3390/resources3010235

6. van Beers D, Graedel TE (2007) Spatial characterisation of multilevel in-use copper and zinc stocks in Australia. J Clean Prod 15:849-861. doi:10.1016/j.jclepro.2006.06.022

7. Rauch JN (2009) Global mapping of $\mathrm{Al}, \mathrm{Cu}, \mathrm{Fe}$, and $\mathrm{Zn}$ in-use stocks and in-ground resources. Proc Natl Acad Sci USA 106:18920-18925

8. Tanikawa H, Hashimoto S (2009) Urban stock over time: spatial material stock analysis using 4d-GIS. Build Res Inf 37:483-502. doi:10.1080/09613210903169394
9. Zhang L, Yang J, Cai Z, Yuan Z (2015) Understanding the spatial and temporal patterns of copper in-use stocks in China. Environ Sci Technol 49:6430-6437. doi:10.1021/acs.est.5b00917

10. Liu G, Müller DB (2013) Centennial evolution of aluminium inuse stocks on our aluminized planet. Environ Sci Technol 47:4882-4888. doi:10.1021/es305108p

11. Brunner PH, Rechberger H (2004) Practical handbook of material flow analysis. Lewis Publishers, New York

12. Fishman T, Schandl H, Tanikawa H, Walker P, Krausmann $\mathrm{F}$ (2014) Accounting for the material stock of nations. J Ind Ecol 18:407-420. doi:10.1111/jiec.12114

13. Fischer-Kowalski M, Krausmann F, Giljum S, Lutter S, Mayer A, Bringezu S, Moriguchi Y, Schutz H, Schandl H, Weisz H (2011) Methodology and indicators of economy-wide material flow accounting: state of the art and reliability across sources. J Ind Ecol 15:855-876. doi:10.1111/j.1530-9290.2011.00366.x

14. van Beers D, Graedel TE (2004) The magnitude and spatial distribution of in-use zinc stocks in Cape Town, South Africa. Afr J Environ Assess Manag 9:18-36

15. Bader HP, Scheidegger R, Wittmer D, Lichtensteiger T (2011) Copper flows in buildings, infrastructure and mobiles: a dynamic model and its application to Switzerland. Clean Technol Envir 13:87-101. doi:10.1007/s10098-010-0278-4

16. Gerst MD (2009) Linking material flow analysis and resource policy via future scenarios of in-use stock: an example for copper. Environ Sci Technol 43:6320-6325. doi:10.1021/es900845v

17. Australian Bureau of Statistics (ABS) (2011) Australian Statistical Geography Standard (ASGS): Main Structure and Greater Capital City Statistical Areas, vol 1. ABS, Canberra

18. Golev A, Corder G (2016) Modelling metal flows in the Australian economy. J Clean Prod 112:4296-4303. doi:10.1016/j. jclepro.2015.07.083

19. Kim YM, Eo YD, Chang AJ, Kim YI (2013) Generation of a DTM and building detection based on an MPF through integrating airborne lidar data and aerial images. Int J Remote Sens 34:2947-2968. doi:10.1080/01431161.2012.756597

20. BlueScope Steel Limted (2011) COLOURBOND steel technical data. Bondor, Australia 